\title{
Startup and Operation of a Metal Hydride Based Isotope Separation Process (U)
}

by

J. H. Scogin

Westinghouse Savannah River Company

Savannah River Site

Aiken, South Carolina 29808

A. S. Poore

A document prepared for FIFTH TOPICAL MEETING ON TRITIUM TECHNOLOGY IN FISSION, FUSION, AND ISOTOPIC APPLICATIONS at Belgirate, Lake Maggiore, from 05/28/95 - 06/03/95.

DOE Contract No. DE-AC09-89SR18035

This paper was prepared in connection with work done under the above contract number with the U. S. Department of Energy. By acceptance of this paper, the publisher and/or recipient acknowledges the U. S. Government's right to retain a nonexclusive, royalty-free license in and to any copyright covering this paper, along with the right to reproduce and to authorize others to reproduce all or part of the copyrighted paper. 


\section{DISCLAIMER}

Portions of this document may be illegible in electronic image products. Images are produced from the best available original document. 
WSRC-MS-94-0488

\title{
Startup and Operation of a Metal Hydride Based Isotope Separation Process (U)
}

\author{
by
}

\author{
John H. Scogin and Anita S. Poore (née Horen) \\ Westinghouse Savannah River Company \\ Savannah River Technology Center \\ Aiken, SC 29808 U. S. A.
}

A paper proposed for presentation at the Fifth Topical Meeting on Tritium Technology in Fission, Fusion and Isotopic Applications

Lake Maggiore, ITALY

May 28 - June 3, 1995

and for publication in the proceedings (Journal of Fusion Technology).

\section{DISCLAIMER}

\begin{abstract}
This report was prepared as an account of work sponsored by an agency of the United States Government. Neither the United States Government nor any agency thereof, nor any of their employees, makes any warranty, express or implied, or assumes any legal liability or responsibility for the accuracy, completeness, or usefulness of any information, apparatus, product, or process disclosed, or represents that its use would not infringe privately owned rights. Reference herein to any specific commercial product, process, or service by trade name, trademark, manufacturer, or otherwise does not necessarily constitute or imply its endorsement, recommendation, or favoring by the United States Government or any agency thereof. The views and opinions of authors expressed herein do not necessarily state or reflect those of the United States Government or any agency thereof.
\end{abstract}

This paper was prepared in connection with work done under Contract No. DE-AC09-89SR18035 with the U. S. Department of Energy. By acceptance of this paper, the publisher and/or recipient acknowledges the U. S. Government's right to retain a non-exclusive royalty-free license in and to any copyright covering this paper, along with the right to reproduce and to authorize others to reproduce all or part of the copyrighted paper. 
John H. Scogin

Savannah River Technology Center

Westinghouse Savannah River Company

Aiken, SC 29808 U. S. A.

(803) $725-3197$

\author{
Anita S. Poore (née Horen) \\ Savannah River Technology Center \\ Westinghouse Savannah River Company \\ Aiken, SC 29808 U. S. A. \\ (803) $725-3028$
}

\begin{abstract}
Production scale separation of tritium from other hydrogen isotopes at the Savannah River Site (SRS) in Aiken, SC, has been accomplished by several methods. These methods include thermal diffusion (1957-1986), fractional absorption (1964-1968), and cryogenic distillation (1967-present). Most recently, the Thermal Cycling Absorption Process (TCAP), a metal hydride based hydrogen isotope separation system, began production in the Replacement Tritium Facility (RTF) on April 9, 1994. TCAP has been in development at the Savannah River Technology Center since 1980. The production startup of this semi-continuous gas chromatographic separation process is a significant accomplishment for the Savannah River Site and was achieved after years of design, development, and testing.
\end{abstract}

\section{INTRODUCTION}

The Thermal Cycling Absorption Process (TCAP) is an efficient and reliable process for separating hydrogen isotopes. Invented by Myung W. Lee of the Savannah River Site (SRS), TCAP has been developed into a dependable production process. Significant advances have been made in column construction, packing materials, operation, and control.

TCAP offers several advantages over cryogenic distillation and was chosen in 1984 as the isotope separation system for the Replacement Tritium Facility (RTF) at SRS. TCAP has a smaller tritium exposed volume, which allows a unit to fit in a typical glovebox, where a cryogenic unit would require a large enclosure. TCAP typically has a small inventory, which reduces the quantity of tritium at risk. In addition, TCAP uses simpler control logic than the continuous cryogenic distillation columns, and operates near ambient temperatures. TCAP's primary disadvantage is the cost of the metal hydride packing material. TCAP can be used in other applications in addition to providing high purity tritium. For instance, it is expected that TCAP can be used in the SRS facilities to clean deuterium to stackable limits, and also clean up other contaminated tritiumdeuterium-protium streams.
A brief overview of TCAP principles and theory is presented, followed by a review of its development, testing, and operation at SRS. Plant operating parameters and throughput are classified and will not be discussed in this paper.

\section{EQUIPMENT AND MATERIALS}

TCAP uses palladium deposited on kieselguhr $(\mathrm{Pd} / \mathrm{k})$ as the active packing material. Kieselguhr is a diatomaceous earth with a large surface area. Palladium is deposited on the kieselguhr granules using a palladium salt solution and then reducing the palladium salt to the metallic state. The material in the TCAP column contains about 55 weight percent palladium, particle size $30-40$ mesh, which allows high gas flow rates.

Basic TCAP hardware consists of two packed tubes connected end-to-end. In the current design, one tube contains $\mathrm{Pd} / \mathrm{k}$ (the column) and the other (the Plug Flow Reverser or PFR) contains kieselguhr, an inert packing material. The PFR allows internal gas transfer to and from the $\mathrm{Pd} / \mathrm{k}$ column with minimal gas mixing. The

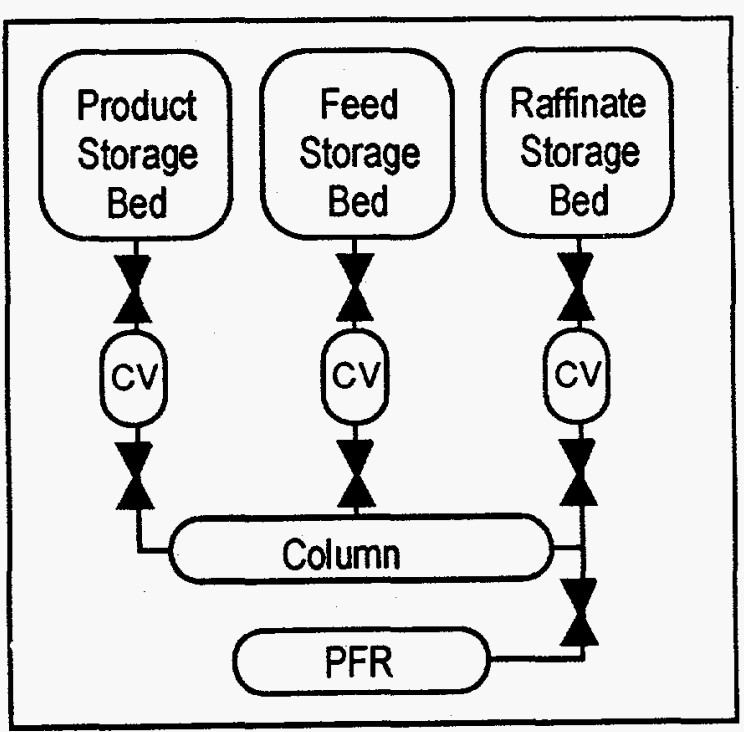

Figure 1. TCAP schematic 
raffinate (preferentially absorbed isotope) takeoff is located between the column and the PFR, the feed point is near the middle of the column, and the product (least absorbed isotope) takeoff is on the end of the column from the PFR. Feed and output from the system are controlled by using calibrated volumes (CVs) to provide a known amount of feed into or output from the column. The feed and the outputs from the system are stored in metal hydride beds using $\mathrm{LaNi}_{4.25} \mathrm{Al}_{0.75}$. To make the unit more compact, the column is formed into a loose coil. Hot or cold nitrogen gas passes through the shell surrounding the $\mathrm{Pd} / \mathrm{k}$ packed coil to heat or cool the metal hydride, which desorbs or absorbs hydrogen isotopes. The TCAP unit and its packing materials have been described previously in further detail. ${ }^{1}$ A schematic of the TCAP unit is shown in Figure 1.

Pressure measurements of the TCAP column, CVs, and PFR are used as control parameters during reflux or production operation. In the RTF unit, a custom designed and fabricated ion chamber at the midpoint of the $\mathrm{Pd} / \mathrm{k}$ column is used to measure the mole fraction of tritium for process control. Thermocouples are used for information (to confirm heating and cooling) and CV pressure-volume-temperature measurements. All TCAP gas samples are analyzed by mass spectroscopy.

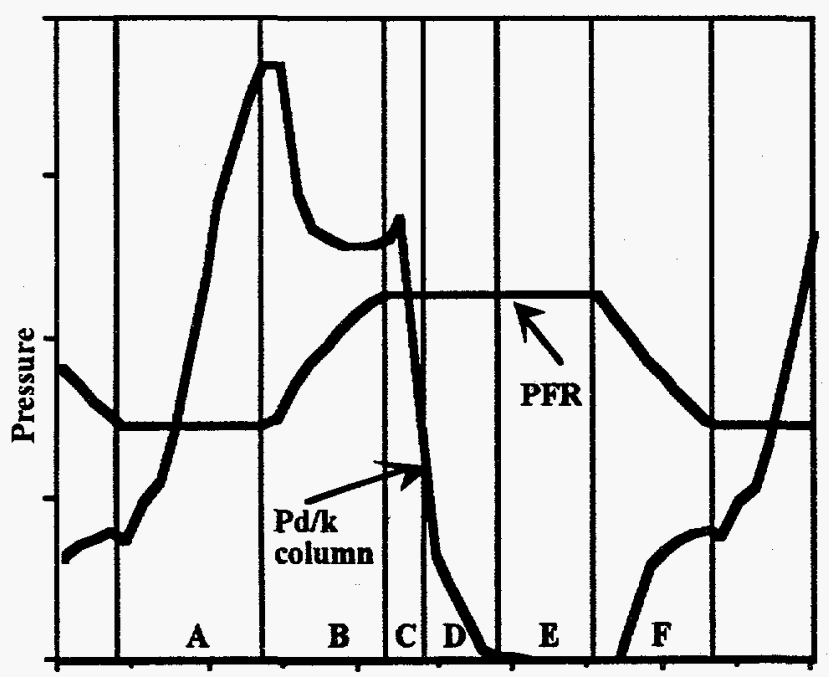

Time

A: Start heating column and fill product and raffinate CVs.

B: Transfer gas from column to PFR

C: Take mid-point sample and start cooling column column

D: Feed column

E: Continue to cool column

F: Transfer gas from PFR to column

Figure 2. Typical TCAP Cycle

\section{TCAP OVERVIEW}

A single TCAP unit is used to separate any two hydrogen isotopes at one time. Development work at SRS involved the separation of protium from deuterium. Production operation of TCAP separates tritium from deuterium (with small amounts of protium). A cascade or series operation involving two or more TCAP units would be required to separate all three isotopes at one time.

\section{A. Principle}

The TCAP operation utilizes the large temperature dependence of palladium's isotopic effect. Palladium preferentially absorbs the lighter hydrogen isotope(s) (deuterium and/or protium) over the heavier isotope (tritium). 1,2 This effect becomes stronger as temperature decreases. The isotopes in the gas phase exchange with those in the solid phase to reach equilibrium rapidly.

\section{B. Modes of Operation}

The $\mathrm{Pd} / \mathrm{k}$ column, filled with a mixture of tritium and deuterium, is thermally cycled to produce isotopic separation. TCAP operation has also been described previously. ${ }^{1}$

There are two basic modes of TCAP operation, reflux and on-line. In reflux mode, the gas in the system is repeatedly cycled back and forth between the $\mathrm{Pd} / \mathrm{k}$ column and the PFR to create or maintain a sharp concentration gradient. In on-line operation, an isotope mixture is fed to the column and enriched gases are removed.

Reflux operation involves four steps: cooling the column, transferring gas from the PFR to the column, heating the column, and transferring gas from the column to the PFR. Cooling lowers the pressure in the column as the gas is absorbed in the hydride. When a low pressure setpoint is reached in the column, the cold gas transfer from the PFR to the column begins. A rise in column pressure at the product end indicates that column is fully loaded and ends the cold transfer. Heating produces high pressure in the loaded column. Once a high pressure setpoint is reached, the hot gas transfer from the column to the PFR begins. When PFR reaches a high pressure setpoint, the hot gas transfer ends. At this point the cycle starts over.

On-line operation may begin once the concentration profile has been established, providing semi-continuous isotopic separation. Three additional steps are added for online operation: output removal, midpoint composition measurement, and feed addition. The cold transfer proceeds as described for reflux operation. Once the hot 
half cycle begins, but before the column high pressure setpoint is reached, both product and raffinate are removed from the column by filling the CVs to a calculated target pressure. At some later time, the CVs are emptied to storage tanks or hydride storage beds. At the end of the hot half cycle, the composition at the midpoint is measured. This measurement provides the fraction of the product isotope at the midpoint, and is used for composition control. The cold half cycle begins after the midpoint composition has been measured. After the cold half cycle begins, the feed is added to the column from the feed CV. The small portions of the column's hydrogen inventory withdrawn during the hot cycle should equal to the amount of feed supplied during the cold cycle. The feed rate remains essentially constant for given operating conditions. This maintains the column profile and inventory, and are discussed later. A typical TCAP online cycle is shown in Figure 2. The feed rate may be changed depending on the required product purities and production throughput. The production rate is dependent on the total cycle time (heating/cooling rate and gas transfer), feed rate, and desired purities of the product and raffinate.

\section{PROCESS CONTROL OVERVIEW}

Control of TCAP's production operation is dependent on two factors: the total $\mathrm{Pd} / \mathrm{k}$ column's hydrogen gas inventory, and the midpoint column concentration.

\section{A. Inventory Control}

The total $\mathrm{Pd} / \mathrm{k}$ column inventory is used to determine the total amount of product and raffinate that will be withdrawn each cycle. While the column is on-line, the total amount of gas in the column should remain constant. Therefore, during each cycle, the same amount of gas should be removed from the column as is introduced as feed. The amount of gas transfer to and from the column is measured using the calibrated volumes (see Figure 1). When the column has finished the absorption, it is assumed to be completely loaded to a constant value. Therefore, inventory control can be achieved by noting the excess (or deficit) of gas in the PFR at the end of the cold cycle. The error in the PFR pressure and the normal feed amount are used to calculate the output amount. If there is an excess of gas in the PFR, more output is taken. Conversely, if there is a deficit of gas, less than the normal output may be removed.

\section{B. Composition Control}

The relative amounts of product and raffinate withdrawn are determined by the concentration of the gas at the midpoint of the $\mathrm{Pd} / \mathrm{k}$ column at the end of the hot half-cycle. TCAP is capable of handling a large range of input concentrations, and works most efficiently when the midpoint composition matches the feed composition.

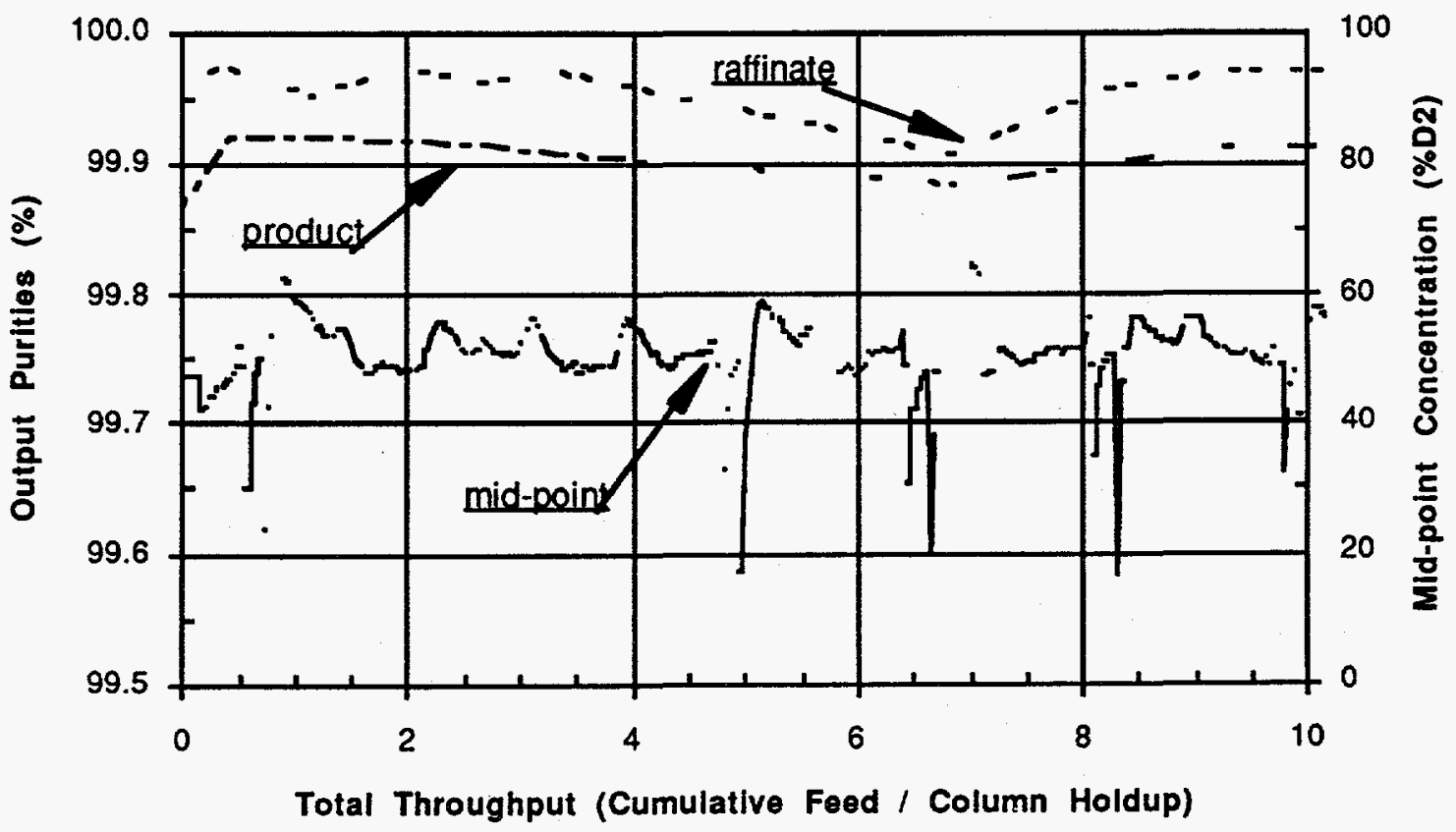

Figure 3. Prototype TCAP Steady-state Feed Composition Results 


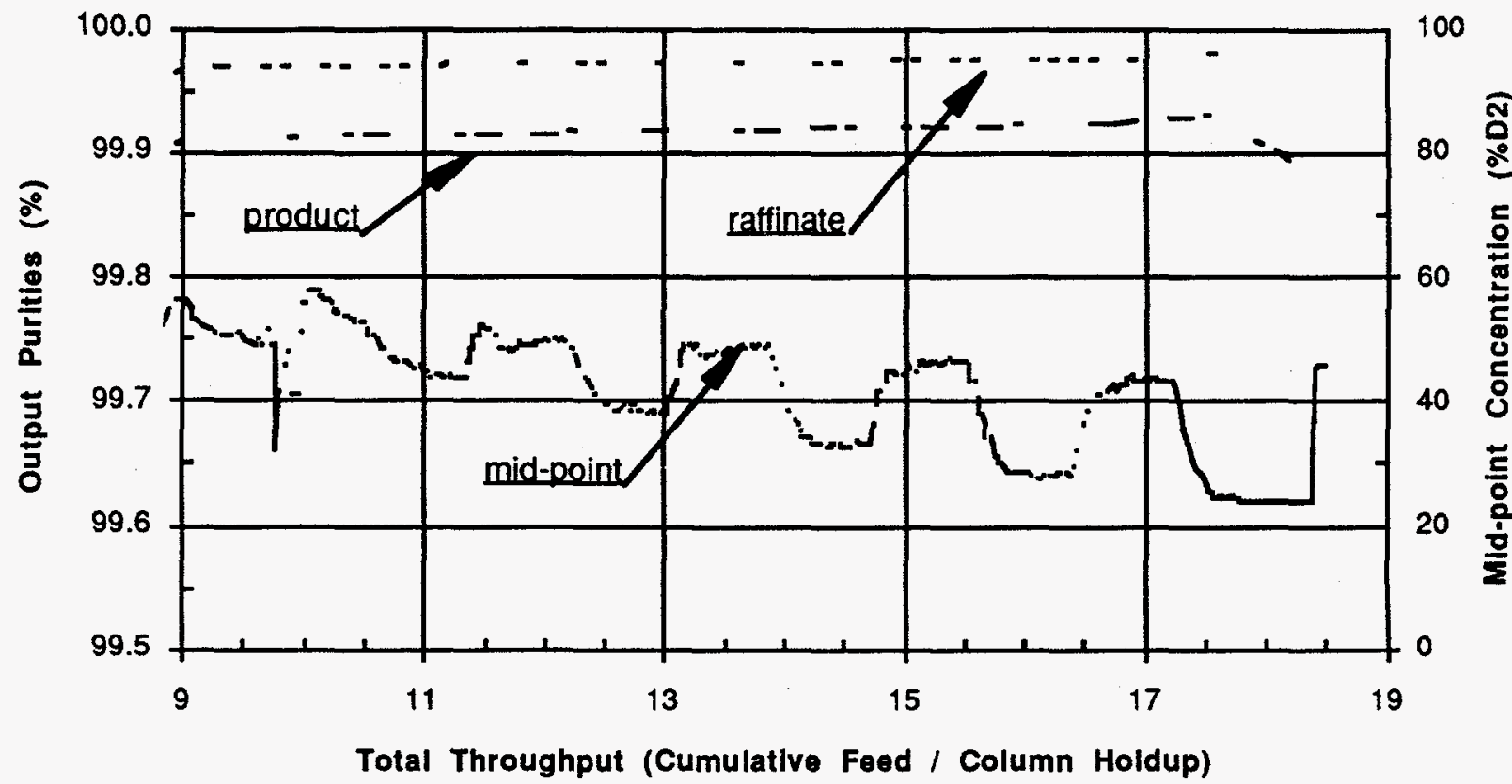

Figure 4. Prototype TCAP Transient Feed Composition Results

Since the feed is added immediately after the midpoint composition is measured, any difference between these two compositions adversely affects the separation profile. Since the feed is not controlled, the midpoint composition is adjusted. In the RTF, an in-line ion chamber is used to measure the amount of tritium at the midpoint of the Pd/K column at the end of the hot halfcycle. In the pilot unit, an automatic mass spectroscopy system was used. The relative amount of tritium (product) and deuterium (raffinate) is adjusted to match the midpoint composition of the column. Therefore, the midpoint composition should approach the feed composition.

\section{TCAP TESTING, STARTUP, AND OPERATION}

Initial prototype TCAP testing using protium and deuterium was performed in a Savannah River Technology Center pilot plant, the Advanced Hydride Laboratory (AHL). The Advanced Hydride Laboratory is a "cold" process demonstration facility that demonstrates the RTF's metal hydride technology by integrating various unit operations into an overall process. Tritium deuterium testing and production operation has been performed in the RTF.

\section{A. Pilot Plant Testing}

Long term steady state and transient operation tests were conducted on the AHL TCAP unit. These operations were designed to demonstrate that the TCAP design and control were stable for long periods and to demonstrate the ability of real time midpoint sampling to control feed concentration variations. Multiple column inventories were run for both the steady-state and transient portions of the test. Previous operation of the prototype TCAP system without real time midpoint analysis had demonstrated separation of mixed hydrogen isotopes ( $55 \%$ protium and $45 \%$ deuterium), resulted in protium and deuterium product streams with purities better than 99.5 mole percent. ${ }^{1}$

The long term steady state AHL TCAP testing demonstrated that product $\left(\mathrm{D}_{2}\right)$ and raffinate $\left(\mathrm{H}_{2}\right)$ purities remained high (greater than 99.8 mole percent) for operation with both steady state and transient feed composition. In steady-state operation, the feed concentration was near $50 \%$ protium (remainder deuterium). The results are shown in Figure 3. The abscissa represents the amount of total amount of throughput processed by the TCAP column relative to the total column inventory. The output purities are represented by broken lines which correspond to the left-hand ordinate. The purities during the transient are all greater than $99.8 \%$ The measured midpoint 
composition as percent $D_{2}$ is shown by the solid line corresponds the right-hand ordinate.

The several regions where a dual spike of low product concentration occurs (at throughputs of about $0.8,4.8$, $6.5,8.2$, and 10 ) are real variations which were created by severe fluctuations in the available cooling. Without sufficient cooling, the column was unable to be fully loaded during the cold half cycle. This caused an excess of pressure in the PFR, which was used in inventory calculations to determine the amount of gas to remove in the next cycle. As the typical feed rate is a small portion of the column volume, even minor variation in the PFR pressure cause large swings in the output amount. An excessive amount of product and raffinate was removed from the column during the hot half cycle, which further depleted the column inventory. In following cycles, the column was fully filled from the PFR, which caused the concentration profile to be greatly shifted toward the product end of the column which produced the mid-point spikes. It should be noted that the system generally recovered from the upsets very quickly and that the output concentrations were uniformly high. The cooling problem was corrected prior to transient testing.

During transient testing, feed composition varied in step changes from about $55 \%$ to $75 \%$ protium. The results are shown in Figure 4. The purities during the transient testing are all greater than $99.8 \%$. These tests on the prototype TCAP verified its operability and stability for a production environment. Some of the improvements in control of the prototype were implemented into the production unit prior to its startup, the others are scheduled to be implemented in the near future.

\section{B. Production Startup}

An intensive six month effort to develop and implement RTF TCAP testing, training, and procedures ensured a successful startup in the SRS Tritium Facilities. A series of tests were run to ensure a smooth startup. The TCAP system was functionally tested using nitrogen to examine line continuities and determine volume calibrations. TCAP's automatic process control sequence, operated by a distributed control system, was then verified using deuterium. In the deuterium test, the TCAP column functionality and integration with the metal hydride storage beds was verified, and the operational modes were demonstrated.

Isotopic separation capabilities were verified by separating a tritium and deuterium feed (using about $40 \%$ tritium - $60 \%$ deuterium) into high purity components. TCAP operation met or exceeded the design criteria for isotopic purities by providing better than 99 mole percent tritium and deuterium. Required production rates are also achieved.
In addition to the tritium/deuterium testing phase of TCAP development, procedures were written to provide operations personnel with the guidance required to operate the TCAP system. Formal classroom and on-the-job training was also conducted to ensure that the operators were qualified and knowledgeable of TCAP operation.

\section{Operation}

TCAP began production in the Replacement Tritium Facility (RTF) on April 9, 1994. TCAP has been operating successfully in a production environment for about one year. During the past year, control parameters have been adjusted slightly to improve performance in both throughput and purity. Some automatic sequence control modifications are being implemented to improve process performance and operator interfaces with the TCAP system. In all cases, TCAP has proven to be an effective, efficient method to separate hydrogen isotopes in the SRS Tritium Facilities.

\section{FUTURE WORK}

Additional plant testing will include optimization of the automatic process control and a one time test to explore the production of stackable (very high purity) deuterium from a low concentration tritium feed (less than one mole percent tritium). Process parameters will also be adjusted to improve process efficiency and throughput.

An advanced TCAP unit has been proposed to test future improvements. One method to increase TCAP's separation capability is to replace the passive PFR with an active inverter column. The PFR currently acts as a spring which holds the gas while that column is heated and cooled, and provides no separation capabilities. An inverter column would be similar to the $\mathrm{Pd} / \mathrm{k}$ column, however, the isotopic effect of the inverter's hydride material would show an opposite temperature dependence than that of palladium. This would allow the inverter to actively separate with the opposite effect of the $\mathrm{Pd} / \mathrm{k}$ column. The enriched raffinate is then removed from the end of the inverter.

An advanced TCAP system will be used to test control improvements, alternate methods of heating and cooling, and to increase operational efficiency. This unit would also demonstrate the ability to cleanup contaminated hydrogen isotopes streams to levels which will allow their release to the environment.

\section{SUMMARY AND CONCLUSION}

TCAP began production in the Replacement Tritium Facility (RTF) on April 9, 1994. TCAP operation met or exceeded the design criteria for isotopic separation of 
providing better than 99 mole percent tritium and deuterium. Required production rates were also met.

TCAP should be considered to replace other hydrogen isotope separation processes. TCAP offers advantages in the areas of handling process transients and upsets smoothly, simpler process control (compared to continuous cryogenic distillation), small size which easily allows the main unit to be placed in a glovebox, and near ambient operating temperatures (simplified heating and cooling). TCAP's tritium inventory is comparable to or lower than that of the continuous cryogenic distillation column(s).

\section{ACKNOWLEDGMENT}

The work described in this paper was prepared in connection with work done under Contract No. DEAC09-89SR18035 with the U. S. Department of Energy. By acceptance of this paper, the publisher and/or recipient acknowledges the U. S. Government's right to retain a non-exclusive, royalty-free license in and to any copyright covering this paper.

\section{REFERENCES}

1. Horen, A. S. and M. W. Lee, "Metal Hydride Based Isotope Separation-Large-Scale Operations", Eusion Technology, Vol. 21, No. 2, Part 2 (March 1992).

2. M. W. Lee, "Metal Hydrides for Hydrogen Isotope Separation," Metal-Hydrogen System Symposium. Stuttgart, Germany (September $4-9,1988$ ). 